\title{
OS CRITÉRIOS DE AVALIAÇÃO E SELEÇÃO DE OBRAS LITERÁRIAS - O PNLD LITERÁRIO 2018
}

\author{
Los criterios para la evaluación y selección de obras literarios - \\ El PNLD Literario 2018
}

Ana Magally Pereira de FREITAS
Universidade Federal da Paraíba
anamagallyufpb@ hotmail.com
https://orcid.org/0000-0002-3544-8177

Israel Niwton da Costa PEREIRA

Universidade Federal da Paraíba niwtonisrael@gmail.com

https://orcid.org/0000-0001-8535-4614

Daniela Maria SEGABINAZI

Universidade Federal da Paraíba dani.segabinazi@gmail.com https://orcid.org/0000-0002-5344-775

RESUMO: Este artigo tem como objeto de estudo e análise o processo de avaliação e seleção de obras literárias do Programa Nacional do Livro Didático e do Material do Livro Didático (PNLD) 2018 - Literário, um programa de promoção da leitura realizado pelo MEC que distribuiu acervos de livros de literatura infantil para bibliotecas e turmas dos anos iniciais. Nosso objetivo é apresentar e discutir os critérios de avaliação e seleção utilizados pelos professores dos anos iniciais do ensino fundamental da rede pública do município de João Pessoa/Paraíba, a partir de dados quantitativos coletados por meio de questionários e análise qualitativa das respostas. Para isto, buscamos em fontes documentais como o edital e guia online e em referenciais bibliográficos os fundamentos que contribuem para a contextualização do programa, a descrição do processo de avaliação e seleção dos livros, a discussão dos critérios usados pela equipe do MEC e pelos professores, assim como equívocos em todo o processo seletivo. De modo geral, os resultados parciais apontam problemas na divulgação e orientação sobre o programa e a escolha das obras, incongruências na seleção dos professores e critérios controversos para a seleção de obras literárias.

PALAVRAS-CHAVE: Critérios de Seleção; Literatura Infantil; PNLD Literário. 
RESUMEN: Este artículo tiene como objetivo estudiar y analizar el proceso de evaluación y selección de obras literarias del Programa Nacional de Libros de Texto y Material de Libros de Texto (PNLD) 2018 - Literario, un programa de promoción de lectura realizado por MEC que distribuyó colecciones de libros de literatura infantil para bibliotecas y clases en los primeros años. Nuestro objetivo es presentar y discutir los criterios de evaluación y selección utilizados por los maestros en los primeros años de la escuela primaria pública en la ciudad de João Pessoa/Paraíba, con base en datos cuantitativos recopilados a través de cuestionarios y análisis cualitativo de respuestas. Para esto, buscamos en fuentes documentales como el aviso público y la guía en línea y en referencias bibliográficas los fundamentos que contribuyen al contexto del programa, la descripción del proceso de evaluación y selección de libros, la discusión de los criterios utilizados por el equipo MEC y por los maestros, así como errores en todo el proceso de selección. En general, los resultados parciales apuntan a problemas en la difusión y orientación sobre el programa y la elección de obras, inconsistencias en la selección de maestros y criterios controvertidos para la selección de obras literarias.

PALABRAS CLAVE: Criterios de Selección; Literatura Infantil; PNLD literario.

\section{CONSIDERAÇÕES INICIAIS}

O presente trabalho expõe uma amostra de dados quantitativos, recolhidos na pesquisa Da Seleção ao Ato de ler: Os livros do Programa Nacional do Livro Didático e do Material Didático (PNLD) 2018 Literário Nos anos Iniciais do Ensino Fundamental, realizada por bolsistas de Iniciação Científica da Universidade Federal da Paraíba (UFPB/PIBIC). Os dados a serem apresentados foram coletados nas visitas às escolas públicas ${ }^{1}$ municipais de João Pessoa, na Paraíba, a partir dos questionários respondidos pelos professores dos anos iniciais do Ensino Fundamental, que participaram do processo de seleção de obras literárias Infantis e Juvenis, oferecidas pelo programa PNLD Literário 2018. Objetivamos apresentar e analisar os critérios de seleção das obras utilizados pelos professores que participaram da escolha do PNLD Literário 2018 em confronto e

\footnotetext{
${ }^{1}$ Das 88 escolas da rede municipal que ofertam os anos iniciais do Ensino Fundamental, visitamos 80 escolas dentre os 9 polos distribuídos pela Prefeitura de João Pessoa - PB. Nessa coleta de dados nas escolas, obtivemos 169 questionários respondidos pelos professores que participaram do processo de escolha do PNLD 2018 Literário. Vale ressaltar que o levantamento foi realizado entre setembro de 2019 até 17 de março de 2020, interrompida em razão do isolamento social imposto pelo agravamento da pandemia da COVID-19.
} 
comparação com os critérios utilizados pela equipe de avaliação do programa, divulgados no guia online ${ }^{2}$. Ainda, em paralelo, buscamos analisar a conformidade entre todos esses critérios, de modo a que possamos refletir e discutir situações de harmonia e também de conflito existentes nos critérios descritos no questionário pelos docentes, bem como, os critérios descritos no edital $^{3}$ e no guia online, que foram os documentos disponibilizados pelo Ministério da Educação (MEC) para todo o processo de seleção do programa.

\section{PNLD 2018 LITERÁRIO: UMA CONTEXTUALIZAÇÃO}

O Programa Nacional do Livro Didático e do Material Didático Literário (PNLD/Literário) 2018, instituído pelo Ministério da Educação (MEC), objetivou disponibilizar obras literárias Infantis e Juvenis destinadas aos alunos da Educação Infantil, dos anos iniciais do Ensino Fundamental I e do Ensino Médio, das escolas públicas das redes federais, municipais e do Distrito Federal e de instituições comunitárias, confessionais ou filantrópicas.

Uma grande parte dos livros foram distribuídos aos acervos das bibliotecas escolares, outros foram distribuídos para o uso em sala de aula. No caso dos alunos dos anos iniciais do Ensino Fundamental, essa distribuição ocorreu da seguinte forma: na categoria 4 ( $1^{\circ}$ ao $3^{\circ}$ ano), foram distribuídas 35 obras para compor os acervos, e esses, deveriam ser destinados à sala de aula; e na categoria 5 ( $4^{\circ}$ e $5^{\circ}$ ano), foram distribuídas 50 obras para compor o acervo da Biblioteca e mais 2 obras para cada aluno dos respectivos anos.

Dessa forma, para que essas obras chegassem até as escolas e aos alunos, elas passaram por algumas etapas de seleção, sendo a primeira através de um edital no qual as editoras e os autores independentes fizeram a inscrição de suas obras no programa, a partir dos critérios presentes no edital. Em seguida, uma equipe de avaliação do MEC, constituída por: Comissão técnica, Equipe responsável pela avaliação de recursos, Coordenação pedagógica, Coordenação adjunta e avaliadores (profissionais da Educação, Linguística e Literatura) fizeram a primeira avaliação das obras.

\footnotetext{
${ }^{2}$ Disponível em: <https://pnld.nees.com.br/pnld_2018_literario/inicio>. Acesso em: 20 abr. 2020.

3 Disponível em: <https://www.fnde.gov.br/index.php/programas/programas-do-livro/consultas/editaisprogramas-livro/item/11568-edital-pnld-liter\%C3\%A1rio>. Acesso em: 20 abr. 2020.
} 
Por fim, a seleção ocorreu pelos professores, uma vez que os títulos aprovados foram catalogados e inseridos em Guia online, que tinha o intuito de apresentar o programa, os critérios de avaliação das obras, o material de apoio ao professor, os títulos das obras selecionadas e aprovadas, bem como a explicação de todo o programa e o processo de escolha. Além disso, a ficha de avaliação utilizada pelo MEC também foi disponibilizada em apêndice no documento, o que pode auxiliar ainda mais esse processo de escolha, por parte dos docentes.

Diante disso, podemos observar que antes de todo o processo de seleção dessas obras, independentemente do momento em que ocorreu, uma regularidade no conjunto de critérios foi imposta; especialmente porque propiciam uma avaliação cautelosa sobre a qualidade do material de leitura para os alunos beneficiários do Programa, sobretudo da leitura de obras de literatura. Tendo em vista essa importância, passaremos à discussão dos critérios utilizados no edital e no guia online.

Antes de passarmos ao assunto proposto, é válido ressaltar que o PNLD/Literário substituiu o Programa Nacional Biblioteca na Escola (PNBE), extinto em 2015. Essa mudança trouxe algumas alterações na seleção e distribuição das obras, como: composição de acervos para as turmas e bibliotecas, distribuição de dois títulos para as turmas de $4^{\circ} \mathrm{e}$ $5^{\circ}$ anos, divulgação de guia online, seleção nas escolas feita pelo professor responsável pela turma e acompanhamento de material pedagógico de apoio para cada obra literária, impresso e em vídeo, para orientar e subsidiar o trabalho do professor. Ainda assim, é interessante notar que existem algumas semelhanças quanto aos critérios de seleção das obras, embora não seja nossa intenção estabelecer essa comparação.

Uma dessas semelhanças - e a única a ser abordada neste trabalho - corresponde a divisão de critérios, uma vez que ambos são ancorados em quatro dimensões avaliativas; dentre elas temos dimensões quanto ao projeto gráfico-editorial, quanto à qualidade literária do texto e quanto à adequação do tema, do gênero literário, da linguagem etc., diferindo apenas na última dimensão, que o PNBE abordou como Dimensão Estatal (MOTA, 2012) e o PNLD 2018 Literário se apoiou na dimensão da qualidade quanto ao material de apoio do professor. 


\title{
CRITÉRIOS DE SELEÇÃO: DO EDITAL AO GUIA ONLINE
}

No que se refere ao programa PNLD 2018 Literário, o edital propõe como primeiro critério a dimensão intitulada como "Qualidade de texto". A preocupação desta dimensão é com a ampliação de um repertório linguístico, que possa proporcionar uma fruição de leitura ao alunado, de uma maneira que a linguagem também seja considerada:

\begin{abstract}
As obras literárias, tanto em língua portuguesa em suas múltiplas variantes (nacional, regional, europeia e africanas), quanto em língua inglesa em suas múltiplas variantes, devem contribuir para ampliar o repertório linguístico dos estudantes e, ao mesmo tempo, propiciar a fruição do uso singular da linguagem que as caracteriza (BRASIL, 2018, p. 31).
\end{abstract}

Com isso, fica claro que durante o processo de escolha, a diversidade deve ser considerada, porém, não de maneira una, com o propósito apenas de ampliar informações diferentes, mas sim, levando em consideração a função estética da linguagem com que essas múltiplas variantes são expostas na obra. Tal preocupação também se segue de uma sequência de critérios, que, de acordo com edital, são analisadas a partir da "exploração de recursos expressivos; consistência das possibilidades estruturais do gênero literário proposto; adequação da linguagem aos estudantes; e o desenvolvimento do tema em consonância com o gênero literário em questão ” (BRASIL, 2018, p. 31).

A "exploração de recursos expressivos" e a "adequação da linguagem aos estudantes", são importantes aspectos a serem analisados, tendo em vista que dizem respeito diretamente ao leitor, pois o primeiro aspecto faz com que ele seja atraído pela leitura, e o segundo faz com que consiga entender e compreender melhor a obra gerando, assim, uma leitura mais prazerosa e eficaz. Além disso, é necessário sublinhar que uma vez alcançado esse despertar prazeroso, despertará também o interesse por novas leituras.

Segundo Colomer (2017), é importante escolher boas obras literárias, que fujam de uma linguagem óbvia ou que fazem apenas uma descrição do que é comum e conhecido para o leitor; isto porque elas possibilitam a ampliação e rupturas de expectativas o que, por sua vez, provoca a apreciação estética e alarga horizontes literários. Para ela, "A 'textura' das palavras que ouvimos em nosso cérebro ao ler é algo essencial para o valor literário de uma obra" (COLOMER, 2017, p. 256), e complementa: 
[...] há que se estar alerta ante o empobrecimento de textos baseados em frases simples e coordenadas que contêm o que o personagem vê ao seu redor ou o que está sucedendo, quase como se se tratasse de um argumento cinematográfico. $\mathrm{E}$, já que o diálogo é muito utilizado nos livros infantis, vale a pena fixar-se especialmente nele (COLOMER, 2017, p. 256).

Além dos critérios sobre a qualidade do texto, o edital destaca a não seleção de obras que contenham um teor doutrinário, panfletário, didático ou religioso. No entanto, podemos afirmar que tal critério, descrito dessa forma, se torna amplo, pois não traz ao avaliador uma contextualização referente a esses critérios. Tal questionamento também surgiu em algumas edições do PNBE, como afirma Mota (2012):

Há um limite sugerido pelos editais que separa as obras literárias das obras predominante doutrinárias, didáticas, religiosas ou panfletárias. Todavia, esse é um limite demasiado amplo, que apenas assinala pela recusa o que não se considera literário. [...] um texto pode ter sido escrito para ser uma obra religiosa e tornar-se literária, a exemplo de $O s$ Sermões, de Padre Vieira. Por outro lado, há gêneros que pela sua própria constituição não podem deixar de desposar certo direcionamento do leitor, como as biografias, as memórias e as autobiografias que traçam e defendem ideais ou no mínimo funcionam como exemplo de vida (MOTA, 2012, p. 311).

Ou seja, considerar esse critério de uma maneira não contextualizada é também uma forma de deixar de lado obras que fazem parte da construção do leitor enquanto ser social. Podemos dizer também que tal critério sugere uma possível contradição com o critério da inclusão de diversidade cultural nas obras - que também é exposto no edital tendo em vista que as culturas indígenas, africanas e afro-brasileiras possuem suas próprias religiões e explicitá-las também é uma forma de ampliar os horizontes de expectativas tanto para si, leitor, quanto para o outro, sociedade. Além disso, outra problemática diante dessa questão é o conflito direto com alguns gêneros literários, que inclusive, estavam incluídos no programa, como por exemplo, os textos da tradição popular, das memórias e dos diários, uma vez que sua circulação é principalmente no âmbito escolar, e na maioria dos casos, é inserida com uma intenção didática. Outro exemplo disso são as lendas e os mitos que carregam em sua essência a explicação de algum fenômeno da natureza ou a origem de culturas, etc. e por isso têm uma intenção didática e pedagógica. Com isso, destacamos a necessidade de discussão e compreensão 
de tal ressalva no edital, ou seja, é preciso considerar não só o gênero literário, mas também o contexto de produção a qual está inserido, para que obras de valor artístico, cultural, social e histórico não sejam reprovadas.

Na segunda dimensão, mais dois critérios aparecem como essenciais: o primeiro é a adequação da obra literária à categoria, considerando a faixa etária; e o segundo critério diz respeito a avaliação da temática dessas obras, que também precisam corresponder à categoria a qual foi inserida. O edital deixa claro essa divisão, alertando inclusive, para às temáticas abordadas de acordo com cada categoria. Por exemplo, na categoria 4, que corresponde do $1^{\circ}$ ao $3^{\circ}$ ano do EF, a primeira temática diz respeito a "descoberta de si", já na categoria 5 , que corresponde ao $4^{\circ}$ e $5^{\circ}$ ano do EF, a primeira temática é o "autoconhecimento, sentimentos e emoções". As duas temáticas podem parecer iguais, contudo, elas divergem quando pensamos nos interesses encontrados nesses grupos por faixa etária.

Segundo Coelho (2000), para que a leitura literária se torne efetiva, é importante que alguns fatores sejam observados, dentre eles a adequação da leitura à etapa de desenvolvimento do leitor, levando em consideração não somente a idade cronológica, mas também a maturidade bio-psíquica-afetiva-intelectual. Logo, podemos observar que a divisão proposta de categorias no edital do programa é por sua vez essencial, tendo em vista que essas obras são distribuídas de acordo com o interesse temático que se relaciona àquele grupo de criança, isto é, do $1^{\circ}$ ao $3^{\circ}$ ano e do $4^{\circ}$ ao $5^{\circ}$ ano, e não às crianças de uma determinada idade.

Quando partimos para o guia online, percebemos que, da mesma forma que o edital, o documento trouxe as informações de acordo com sua categoria, bem como a temática em que cada livro se encontrava. O que o diferenciou do edital foi a não inserção dos enfoques relacionados ao tema, e a inserção de resenhas sobre cada uma das obras.

A terceira dimensão abordada é o Projeto gráfico-editorial, que traz critérios quanto a materialidade dos livros, levado em consideração a coerência entre o texto principal, os paratextos como o prefácio, as intervenções gráficas e as ilustrações da obra, uma vez que, se tais aspectos não corresponderem uns aos outros, podem vir a comprometer o ato da leitura. Pensando nos livros de Literatura Infantil e Juvenil, que neste caso são os livros distribuídos nesse programa, alguns elementos citados são, por sua 
vez, composição da própria narrativa, como afirma Colomer:

Os elementos materiais de alguns livros infantis apresentam características particulares. Pode ser que estes aspectos obedeçam simplesmente a critérios de publicações editoriais. Mas pode ocorrer que tenham sido escolhidos para contribuir à interpretação da obra em estreita interdependência uns com os outros (COLOMER, 2007, p. 272).

Ou seja, a mudança de um formato, a distribuição e a cor de fundo das páginas, a relação entre o texto e a imagem, ritmo, movimentação e etc., fazem parte da leitura, e, consequentemente, se fazendo necessária para o alcance da compreensão. Outros critérios são expostos pelo edital, como por exemplo, a necessidade de que exista nas obras um apoio para textual, no qual seja contextualizado a biografia do autor e a respectiva obra, de maneira que venha a possibilitar uma maior ampliação nas possibilidades de leitura.

Ainda, no critério "Projeto gráfico-editorial", o edital expõe que "Como essas informações têm por objetivo a ampliação das possibilidades de leitura dos estudantes, elas devem ser relevantes e consistentes, porém, em linguagem apropriada à faixa etária esperada para os estudantes dos Anos Iniciais" (BRASIL, 2018, p. 38). O que nos traz mais uma vez a afirmativa de que tais critérios precisam estar relacionados não só às categorias, mas também a todos critérios distribuídos no edital.

A última dimensão exposta no edital refere-se à "Qualidade do manual do professor digital". Tal dimensão acrescenta ao programa um aspecto mais abrangente no que diz respeito ao trabalho com a leitura literária, uma vez que este material proporciona aos docentes, possibilidades metodológicas de leitura, bem como outros subsídios didáticos. Neste edital foi considerado facultativo, o que nos levou a não o tratar como objeto da nossa pesquisa e, portanto, não faz parte de nossa análise.

Diante do exposto, podemos perceber que independentemente dos pontos analisados a respeito do edital e do guia, os critérios de avaliação e seleção das obras são expostos de maneira esclarecedora, a fim de auxiliar os docentes durante o processo de escolha, trazendo informações que vão desde o funcionamento do programa e sua importância para a escola, até o passo a passo de todo o processo. Logo, percebemos tais documentos como necessários ao processo de seleção realizado pelo professor, pois favorecem e dão apoio a escolhas mais criteriosas e fundamentadas. 


\section{SELEÇÃO DAS OBRAS DO PNLD 2018 LITERÁRIO: AS ESCOLHAS DOS DOCENTES}

Antes de seguirmos com a análise dos critérios usados pelos professores, destacamos a incongruência entre as respostas dos professores, o edital e o guia quanto ao acesso integral das obras literárias durante o processo de escolha. No edital, na cláusula 11.1.2, temos a seguinte informação: “As obras literárias aprovadas serão disponibilizadas em sua integralidade para visualização pelos professores durante o processo de escolha" (BRASIL, 2018, p. 15), enquanto o guia online afirmava que os professores teriam acesso apenas as resenhas dessas obras:

\footnotetext{
Para contribuir com a escolha de obras que melhor atendam aos objetivos e necessidades de sua escola, de sua(s) turma(s), alinhadas ao seu planejamento pedagógico e em conformidade com a Base Nacional Comum Curricular (BNCC) para o Ensino Fundamental e as Diretrizes e Orientações Curriculares para o Ensino Médio, este Guia apresenta: a) os critérios de avaliação que orientaram a seleção das obras, b) uma breve descrição dos aspectos técnicos dessas obras e c) as resenhas das obras aprovadas (BRASIL, 2018, p. 7).
}

Com isso, quando passamos as respostas dos professores quanto aos critérios que eles utilizaram, notamos que algumas descrições sugeriam a leitura de algumas obras durante a seleção, mas não temos como confirmar se foi das resenhas ou das obras integrais. A princípio, acreditamos que se tratasse das resenhas, pois o guia online seria o principal meio de informação no processo de escolha. No entanto, veremos no decorrer da nossa análise que alguns critérios descritos pelos docentes não correspondem a tal suposição.

Apesar de o guia online ser o ponto de partida para o processo de seleção e escolha das obras pelos professores, apenas $20 \%$ dos que responderam ao questionário disseram que seu principal critério foi o guia, bem como as resenhas disponibilizadas pelo MEC. Se pensarmos na importância do quesito, veremos que a porcentagem é consideravelmente baixa, uma vez que esse documento contém informações sobre o programa, sobre o processo de seleção das obras pelo MEC, sobre o processo de escolha nas escolas, além de conter a catalogação dos livros por categorias e as fichas de avaliação utilizadas pela equipe de avaliação do MEC. 
Em contrapartida, temos com $70 \%$ o critério "Faixa etária/Nível de turma", que conforme exposto anteriormente é um critério válido e importante, pois em cada fase de leitura e crescimento da criança surgem novos interesses e desafios. No entanto, questionamos dois aspectos, o primeiro é que o guia online já faz a divisão das obras por categoria, portanto já temos a indicação considerando a faixa etária; tal seleção é feita, como vimos, tanto no momento da inscrição das obras, quanto no momento da avaliação pela equipe do MEC, ou seja, os livros já estavam catalogados a partir desse critério. Além do mais, é possível crer que os professores tenham dado essa resposta pelo fato de que a lista disponibilizada dos livros se referiam aos alunos do $1^{\circ}$ ao $5^{\circ}$ ano e, mesmo que a escolha tenha sido feita em conjunto (professores da escola), como orienta o guia, os professores deveriam escolher os livros referente a sua turma específica.

O segundo ponto é que tal resposta pode ter sido dada por outros motivos, como por exemplo o fato de terem lido as resenhas disponibilizadas ou os livros na integralidade - como disse o edital - e, por mais que o guia tenha sido seu ponto de partida, o docente preferiu dizer que diante das suas leituras ele utilizou o critério em questão. Outra hipótese é que o docente poderia estar com pressa para responder o questionário e esquecendo-se dos critérios que utilizou, preferiu responder de um modo amplo, uma vez que tal critério faz parte de um método geral para seleção de obras, quando pensamos na Literatura Infantil e Juvenil.

Outro critério exposto pelos professores foi o "Tema", que totalizou 30\% das respostas. E assim como o critério anterior, esse também estava incluído tanto no edital quanto no guia online. No edital, por exemplo, além desse critério vir acompanhado pelo enfoque da temática, também vinha especificando a qual categoria, ou seja, a qual faixa etária, esse tema era destinado. E apesar desses temas serem bastante semelhantes entre as categorias 4 e 5, também possuíam suas diferenças. Como por exemplo, os temas destinados a categoria 4, que foram: a) descoberta de si; b) família, amigos e escola; c) o mundo natural e social; d) diversão e aventura; e e) outros. E os temas destinados a categoria 5, que foram: a) autoconhecimento, sentimento e emoções; b) família, amigos e escola; c) o mundo natural e social; d) encontros com a diferença; e) diversão e aventura; e f) outros.

Como é possível perceber, além de a categoria 5 ter um item de tema a mais, que 
é o caso de "encontros com a diferença", o tema "família, amigos e escola", mesmo sendo igual a categoria 4 , possuem enfoques diferentes. Para os alunos do $1^{\circ}$ ao $3^{\circ}$ ano (Categoria 4), o enfoque se relaciona com as "Primeiras experiências interpessoais e sociais das crianças, permitindo a construção de percepções e questionamentos sobre si e sobre o outro" (BRASIL, 2018, p. 35), enquanto que o enfoque para os alunos do $4^{\circ}$ e $5^{\circ}$ ano (Categoria 5) tem relação com "Personagens que estejam em interação com o mundo que lhe é imediato, na relação com família, amigos e professores, permitindo a construção de percepções e questionamentos sobre si e sobre o outro" (BRASIL, 2018, p. 35-36).

Tal discussão também é explicitada nos critérios de avaliação do edital: "Na avaliação, serão observadas a capacidade de motivar a leitura e a exploração artísticas dos temas, bem como o potencial para ampliar as referências estéticas, culturais e éticas do leitor" (BRASIL, 2018, p. 31). Ou seja, o critério "tema" deve ser analisado em harmonia com outros critérios avaliativos.

Para Mota (2012), algumas obras apresentam dificuldade quanto a coerência entre o tema e a qualidade de seu texto literário, tendo em vista que, nesses casos, o tema peca por excesso, levando em consideração apenas o assunto e deixando de lado outros recursos igualmente essenciais, como por exemplo recursos expressivos e estéticos da linguagem. Ainda, segundo o autor, outras problemáticas surgem quando apenas o tema é o centro da obra:

[...] Não são poucas as obras que apresentam dificuldade em dar um tratamento coerente ao tema que abordam, revelando-se textos malogrados. Há poemas que pecam pelo excesso de imagens e outros que só são designados como poemas porque se apresentam na forma de versos, tamanho o prosaísmo que encerram. Há narrativas que não desenvolvem seus personagens ou que os perdem ao longo das páginas sem que se saiba bem a que razão surgiram na história. Há obras cujas as partes se desencontram, os poemas com estrofes descontínuas ou com recursos melódicos conflitantes e as narrativas com ações gratuitas e trama frouxa, além de reviravoltas e finais pouco convincentes (MOTA, 2012, p. 313-314).

Nota-se que esse critério não é simples, posto que deve ser analisado em conjunto com os demais. Logo, podemos entender que, se os professores se utilizaram desse critério, é porque possivelmente analisaram a obra, o que nos sugere a hipótese de que tiveram acesso a essas obras, de maneira integral, ou que já as conheciam. Assim, ao 
analisarmos algumas respostas podemos perceber que tal hipótese aponta para duas questões; a primeira está relacionada à forma com que foi usado o critério baseado no tema em duas respostas de professores de escolas diferentes,como veremos abaixo:

Tabela 1: Resposta dos professores ${ }^{4}$ quanto aos critérios utilizados no processo de seleção das obras

\begin{tabular}{|l|l|}
\hline Professor (a) 78. & $\begin{array}{l}\text { Resposta - Buscamos trabalhar com temas que sejam importantes para } \\
\text { ajudar na auto-estima [sic] dos alunos e que desperte curiosidade dos } \\
\text { alunos. }\end{array}$ \\
\hline Professor (a) 70. & $\begin{array}{l}\text { Resposta - Os critérios para a escolha foi através reunião [sic] e } \\
\text { discussões onde a escolha foi a partir [sic] das temáticas envolvendo } \\
\text { étnico raciais. }\end{array}$ \\
\hline
\end{tabular}

Fonte: Questionário da Pesquisa.

Com isso, notamos que o critério foi utilizado de maneira equivocada por alguns professores, visto que o assunto abordado teve importância maior na utilização do critério, do que a literariedade das obras. Outras respostas semelhantes foram descritas, como por exemplo, o tema precisar ser mais simpatizante pela escola/comunidade, serem temas atuais com relação a prática pedagógica, entre outros. Ou seja, o tema foi escolhido somente por seu assunto, com o intuito de complementar atividades e/ou projetos realizados pela escola que, em sua maioria, como vimos, é de pura conscientização, portanto, uma literatura utilitária, pretexto de outros conteúdos escolares que não a próprio trabalho de formação de leitores.

Por outro lado, temos as respostas que confirmam de maneira implícita a leitura das obras de maneira integral, como notamos nas respostas de dois professores de escolas diferentes:

Tabela 2: Resposta dos professores quanto a descrição do processo de escolha

\begin{tabular}{|l|l|}
\hline Professor (a) 38. & $\begin{array}{l}\text { Resposta - Em reunião pedagógica com a supervisora, que expôs o } \\
\text { material que a escola recebeu, kits de livros e uma ficha para } \\
\text { efetivar a devida escolha. Conforme roteiro oficial. }\end{array}$ \\
\hline Professor (a) 128. & $\begin{array}{l}\text { Resposta - Houve reunião na escola nos falando sobre a escolha } \\
\text { dos livros literários. Foi nos dado algumas amostras e pediram para } \\
\text { que conhecêssemos o autor, quem ilustrou, etc. }\end{array}$ \\
\hline
\end{tabular}

Fonte: Questionário da Pesquisa.

\footnotetext{
${ }^{4}$ Para identificação dos professores participantes, optamos pela enumeração de 1 a 169 , que corresponde a quantidade de questionários respondidos durante as visitas nas escolas.
} 
O que pode nos revelar que os critérios acerca dos temas descritos pelos professores foram de fato observados a partir da leitura integral das obras, o que não torna esses critérios corretos, mas incoerentes quando pensamos que mesmo tendo acesso integral à leitura, os professores só analisaram o tema pelo tema, com vista ao encaixe da literatura em projetos, conteúdos, etc. Além disso, tais informações nos mostra a segunda problemática, que se relaciona ao fato de a escola receber livros para o processo de escolha, uma vez que no Guia, em "Normas de Conduta”, temos a seguinte informação:

[...] Por sua vez, é proibido às escolas: 1. Aceitar, a qualquer momento, vantagens, presentes ou brindes dos representantes em razão da escolha dos materiais do PNLD; 2. Permitir acesso de representantes nas dependências da escola durante o período de Registro de escolha; 3. Permitir acesso de representantes aos dispositivos em que é realizado o registro de escolha; 4. Disponibilizar, a qualquer tempo, espaço público para a realização de eventos promovidos pelos representantes; 5. Permitir a qualquer tempo, a participação dos representantes em eventos promovidos pela escola; entre outras vedações (BRASIL, 2018, p. 2425).

Ou seja, segundo o guia, em hipótese alguma a escola deveria receber amostras de livros ou manter qualquer contato com editoras e/ou autores independentes durante todo o processo de seleção. E, apesar de no edital não haver informações quanto a proibição do contato entre editoras e/ou autores independentes e a escola, também não diz que esse contato pode acontecer, uma vez que o edital menciona que as obras estariam disponíveis online.

Seguindo com as mesmas questões do critério anterior, estão os critérios "Projeto-gráfico" com 19\% e "ilustração" com 18\%. O primeiro, como já citado, trata de uma das dimensões de avaliação do programa que aparece tanto no edital quanto no guia. O segundo é um critério que atravessa duas dimensões: qualidade de texto e projetográfico, aparecendo no edital e também no guia.

É importante ressaltar que, quanto ao projeto gráfico, o edital trouxe um modelo padronizado para os livros, tanto no que diz respeito ao tamanho, quanto ao papel, acabamento, miolo, etc. Contudo, tais restrições atrapalham o processo de compreensão da leitura e também empobrecem a proposta original da obra, uma vez que são afetadas pela necessidade de se encaixarem no edital. 
Como podemos observar, alguns projetos gráficos fazem parte da composição da narrativa, logo, sem esse suporte, o processo de apreciação e entendimento durante a leitura pode ficar comprometido. Por isso, cabe o questionamento: as obras que necessitam desse suporte ficaram de fora no momento da inscrição do programa? Ou foram adaptadas? E se foram, a partir de quais critérios isso aconteceu?

No que diz respeito a utilização desses critérios, ilustração e projeto gráfico, utilizados pelos professores no momento da seleção, podemos afirmar que não seria possível, uma vez que, a análise de ambos necessitava do acesso a obra completa e física, pois, como podemos observar se as ilustrações correspondentes ao texto verbal são coerentes, senão pela análise do livro em um todo? Ou, como observar se o suporte gráfico possui tal formato, tal espessura, e se essas dialogam e de que forma, senão pela análise física?

Nas respostas de alguns professores, questões como tamanho de letras, grafia, qualidade de impressão, texto curto, conformidade entre o texto verbal e as ilustrações, apareceram descritas como critérios utilizados, e como é possível perceber se tratam de quesitos que necessitam da análise do livro como um todo. À vista disso, apresentamos abaixo algumas respostas de professores de escolas diferentes:

Tabela 3: Respostas dos professores quanto aos critérios de avaliação das obras

\begin{tabular}{|l|l|}
\hline Professor (a) 140. & $\begin{array}{l}\text { Resposta - A escolha foi feita em grupo, analisando o enredo, } \\
\text { ilustração, linguagem e o público alvo. }\end{array}$ \\
\hline Professor (a) 148. & $\begin{array}{l}\text { Resposta - Os critérios utilizados para avaliar e selecionar os } \\
\text { livros, foram a pertinência dos valores para a turma, a qualidade do } \\
\text { trabalho gráfico, a coerência texto verbal e não-verbal e as riquezas } \\
\text { dos detalhes deste para inferências, entre outros. }\end{array}$ \\
\hline
\end{tabular}

Fonte: Questionário da Pesquisa.

Se levarmos em consideração que as leituras dessas obras foram feitas a partir das resenhas e das capas dos livros disponibilizadas pelo MEC, veremos que a utilização de tais critérios é inviável, pois uma resenha ou uma capa da obra não é a obra integral. Se pensarmos na leitura online, que segundo o edital é disponibilizada, teremos uma melhor condição de usar esses critérios. Contudo, ainda de maneira limitada, mesmo porque não poderíamos ver a qualidade do papel, da impressão, nem a riqueza de detalhes de um livro. Restando apenas a possibilidade de utilização desses critérios - em um todo -, se os 
professores tivessem acesso à obra impressa e em seu suporte físico, que como confirma a tabela 2, existe uma chance de ter acontecido.

Apesar disso, tais critérios possuem uma grande importância quando se trata de avaliação de obras Infantis e Juvenis, pois, segundo Mota (2012), são critérios que devem ser percebidos e avaliados, tendo em vista que pode vir a ocorrer excessos ou escassez de qualidade, afastando o leitor da leitura da obra:

\begin{abstract}
Há que se observar, na dimensão material, a relação de coerência entre a capa e o conteúdo do livro, assim como a adequação entre ilustração e o texto verbal. [...] Na tentativa de atrair o leitor, o projeto gráfico termina emprestando excessiva modernidade à capa, contrariando o interior do livro. O inverso também acontece, ou seja, livros com capas excessivamente sóbrias, sem nenhum convite à curiosidade do leitor, apesar de trazerem histórias para lá de divertidas. Nos dois casos, as capas não funcionam como portas de entrada para obra. Ao contrário, são elementos do projeto gráfico editorial que distanciam o leitor ou conduzem a uma escolha equivocada quanto ao tipo de livro que ele desejaria ler (MOTA, 2012, p. 310).
\end{abstract}

Ou seja, tais análises quando não bem avaliadas, podem vir a afastar ou aproximar o leitor, ampliando ou desestimulando sua leitura. Por esse motivo é preciso acentuar que os critérios descritos pelos professores são coerentes quanto aos métodos de seleção e avaliação das obras, entretanto, são incoerentes se analisarmos os critérios em confronto com a disponibilidade das obras que o programa oferece no processo de escolha.

Além desses critérios, outros que não estavam no edital e no guia se fizeram presentes nas respostas dos professores, como "Título/autor" que obteve $23 \%$ nas respostas. Sobre esse dado, nos indagamos: O que garante que a partir do título e do autor saberemos se uma obra é de boa qualidade ou não? Além disso, o que mais chama a atenção é a porcentagem de professores que disseram escolher esse "critério", especialmente, em contraste com o critério "Guia online" com apenas 20\%, principal caminho para a orientação das escolhas. Escolher pelo título ou autor é algo bastante arriscado, que nem sempre garante boas leituras e pode fazer com que os alunos percam a oportunidade de conhecer outras obras de qualidade literária e de outros autores, ampliando o repertório de leitura.

Segundo Colomer (2007), selecionar requer orientação, pois a cada ano uma grande variedade de livros é lançado pelas editoras e essas edições são cada vez mais 
diversificadas. Por essa perspectiva, é possível crer que escolher pelo título é como jogar com a sorte e escolher pelo autor porque já lemos algo dele e gostamos ou porque ele é bastante comentado, é supor que esse sempre terá livros que abordam x coisas, ou que trazem x elementos de qualidade. Para a autora, “[...] a atitude majoritária da escola é procurar assegurar-se o controle de um certo nível de qualidade das leituras por ela facilitadas" (COLOMER, 2007, p. 128).

Por outro lado, quando observamos as respostas dos professores, percebemos que podem ter existido alguns problemas quanto à utilização desse critério. Dois deles ficaram mais evidentes: a falta de orientação correta por parte da gestão escolar que, possivelmente, não disponibilizou ou orientou a leitura do guia, somente a lista das obras; e/ou a escassez de tempo para realizar uma escolha mais detalhada e atenciosa. Abaixo temos duas respostas de professores de escolas diferentes que apontam para essas conclusões:

Tabela 4: Respostas dos professores quanto aos critérios de avaliação das obras

\begin{tabular}{|l|l|}
\hline Professor (a) 13. & $\begin{array}{l}\text { Resposta - Após a reunião de planejamento "escolhi" os que } \\
\text { sobraram, pois não havia mais tempo. }\end{array}$ \\
\hline Professor (a) 148. & $\begin{array}{l}\text { Resposta - Foi entregue um formulário referente ao 2 ano, um } \\
\text { catálogo com as sínteses dos livros e os códigos de referência. O } \\
\text { prazo de entrega foi no mesmo dia em que recebemos as } \\
\text { orientações, então no fim do horário do trabalho estendi [sic] para } \\
\text { deixar as escolhas prontas. Os procedimentos posteriores não tive } \\
\text { conhecimento. }\end{array}$ \\
\hline
\end{tabular}

Fonte: Questionário da Pesquisa.

Esclarecemos que na resposta do(a) professor(a) 1, quando ele(a) fala sobre escolher os "que sobraram", ele(a) refere-se a questão de que os livros não poderiam se repetir entre os anos, ou seja, os livros escolhidos para o $1^{\circ}$ ano deveriam ser diferentes do $2^{\circ}$ ano e assim por diante, logo ele(a) quis dizer que teve que escolher os que restaram na lista entre os títulos disponíveis.

Ao passarmos para as observações das respostas,podemos ver que nas duas a menção a falta de tempo evidencia o grande contratempo e a dificuldade para o processo de escolha, porém, também percebemos implicações quanto a gestão escolar, pois nas duas respostas aparenta-se que o professor só escolheu porque se tratava de uma exigência do Guia, mas não lhe foram dadas condições adequadas para tal. 
O tempo disponibilizado para todo processo de escolha seria, de acordo com o Guia entre o dia 18/10/2018 ao dia 31/10/2018, ou seja, 13 dias, um prazo exíguo considerando que o professor possui uma carga horária extremamente estendida, com projetos da escola e também da prefeitura, como é o caso do Educação pra Valer ${ }^{5}$ e o Acelera ${ }^{6}$.

Diante dessas questões é possível reafirmar que, analisando a partir de todo um contexto que envolve a rotina do professor, o tempo disponibilizado para a seleção das obras foi insuficiente e limitado para uma escolha criteriosa. Apesar da falta evidente de organização gestacional, o professor não pode simplesmente abandonar todo o seu dia-adia para se debruçar somente nas análises para a escolha e, por outro lado, não pode também escolher de qualquer forma, sem critérios, ou utilizando-os por instinto. Nesse sentido, fica claro que se faz necessário um tempo maior para essa escolha e um debruçamento melhor por parte dos docentes, isso se o interesse for de fato distribuir e selecionar livros de boa qualidade literária para os alunos.

Por fim, mais dois critérios foram apontados, conteúdo e gênero. Assim, com $12 \%$ ficou o critério "Conteúdo", que também não foi citado no edital e nem no guia. Para esse, duas hipóteses se impõem: a primeira é que os docentes se referiam ao conteúdo narrativo, ou seja, a história em si; e a segunda hipótese seria ao conteúdo contido na narrativa, ou seja, a mensagem da história. No primeiro caso, a hipótese é um pouco ampla, uma vez que, supomos que os professores leram as obras online, mas, ainda assim, de que conteúdo narrativo estão se referindo? Na segunda hipótese, surge um grande problema, que é analisar o texto literário como conteúdo, isto é, como um complemento disciplinar e utilitário.

Escolher um livro literário pensando em seu conteúdo pedagógico é como exterminar todo o encanto imagético que a arte pode proporcionar. É quebrar a magia da leitura, provocando uma aversão, ao invés de uma proximidade. Além disso, é perpetuar a

\footnotetext{
${ }^{5}$ O Programa Educação pra Valer surgiu no ano de 2018, na cidade de Sobral - CE, e foi implantado às escolas de rede municipal do município de João Pessoa - PB no ano de 2019, com o intuito de ampliar os resultados do Programa Geração Alfabetizada, que é realizado pela Secretário de Educação e Cultura (SEDEC) da capital.

${ }^{6}$ Acelerando o Saber é um projeto que auxilia alunos com defasagem de no mínimo dois anos em relação a idade esperada para determinado ano escolar. Tal projeto é realizado pela Prefeitura Municipal de João Pessoa (PMJP), por meio da Secretaria de Educação e Cultura (SEDEC), em parceria com a Fundação Volkswagen, juntamente com o Centro de Estudos e Pesquisas em Educação, Cultura e Ação (CENPEC).
} 
visão errônea das funções literárias, como afirma Colomer:

[...] a função educativa da literatura infantil foi a grande estrela dos debates sobre seleção de livros, porque a sociedade costuma estar mais preocupada com a educação moral do que com a educação literária das crianças e essa é a função que "realmente" a maioria ainda hoje atribui à literatura infantil (COLOMER, 2007, p. 134).

Por essa perspectiva, é possível perceber que o enfoque dado ao conteúdo faz com que os alunos percam a apreciação artística que cada obra literária traz. O mesmo acontece com o critério "tema", quando utilizamos pensando apenas no assunto que circunda a narrativa, pois, "[...] cabe perguntar-se desde quando o tema do qual trata determinada obra determina sua qualidade artística e se é possível sintetizar uma narrativa literária dizendo simplesmente, por exemplo, que "fala sobre anorexia"." (COLOMER, 2007, p. 135). A literatura, seja ela infantil, juvenil ou não, existe em função dela mesma, e não requer um apoio para se fazer compreendida e/ou apreciada.

Seguindo nossa análise a partir dos dados quantitativos temos com $14 \%$ o critério "gênero", presente tanto no edital quanto no guia, uma vez que faz parte da dimensão “Adequação de categoria, de tema e de gênero literário". De fato, esse era um critério viável para os professores, pois eles poderiam escolher quanto ao gênero literário, isto é, poesia, crônica, contos, fábulas, etc., uma vez que também estavam demarcados no guia. Tal porcentagem nos revela que havia uma preocupação quanto a diversidade das obras por uma boa parte dos professores.

Por último, 5\% dos professores não responderam a questão sobre os critérios utilizados e $13 \%$ ficaram entre as opções "Outros", que correspondem a um conjunto de critérios que tiveram uma quantidade mínima de escolha, entre eles estão: capa, datas comemorativas, interesse do professor, objetos de aprendizagem, e etc. Ou seja, critérios que não estão em conformidade nem com os documentos de auxílio para escolha, nem com os critérios de seleção e avaliação de obras literárias Infantis e Juvenis, mas que certamente fazem parte dos conhecimentos e saberes docentes que levam a escolha de livros para leitura em sala de aula. 


\section{CONSIDERAÇÕES FINAIS}

Ao reunirmos os dados quantitativos dessa pesquisa, e ao realizarmos sua análise, constatamos que alguns empecilhos existiram desde o momento da seleção e avaliação dos livros por parte do programa, até o processo de seleção e escolha por parte dos professores.Em ambos os casos, depreendemos que foram problemas quanto a organização, e no que diz respeito a escolha dos professores, podemos afirmar que a falta de uma formação adequada para esse processo, juntamente com a falta da leitura dos documentos balizadores, um possível desconhecimento e desinteresse pelo programa, além da existência da falta de uma orientação adequada e fundamentada da literatura infantil e juvenil, provocou os conflitos expostos, e possivelmente gerou uma escolha baseada em deduções sem consistência.

Examinamos também que boa parte dos critérios utilizados pelos docentes, mesmo alguns deles estando em conformidade com o edital e o guia, foram gerais e aleatórios; ora conduzidos por orientações da gestão escolar, ora alicerçados por saberes docentes provenientes, talvez, da prática, do estudo teórico e das formações, inicial e/ou continuada sobre formas de seleção e avaliação de obras Infantis e Juvenis. Tal entendimento decorre do confronto entre as respostas obtidas pelo questionário e a leitura e análise do guia e edital do programa.

Não obstante, o que mais nos é revelado pelas respostas dos professores é a utilização de critérios a partir do seu fazer pedagógico, isto é, a partir do uso da obra como objeto de transmissão de uma mensagem ou de um ensinamento, evidenciados pela preocupação com o tema e o conteúdo. Ainda, como recurso para ensino da leitura e escrita enquanto processos ligados a alfabetização, especialmente, realçado pelo critério "faixa etária".

Então, como podemos verificar por esta pesquisa, a escola, de modo geral, até o presente, está bastante preocupada com a educação dos (as) alunos (as), sempre aproveitando as oportunidades para realizar tal intuito. Todavia, carece de um planejamento e organização para que ações educativas e políticas públicas adentrem seu espaço com a devida dosagem de conhecimento teórico, pois esse "educar" pode tornar-se algo não apreciado, não absorvido e, por isso ineficaz para o ensino de literatura, para a leitura literária e a experiência estética; principalmente quando se trata de seleção de obras 
e mediação da leitura literária, uma vez que esta não busca educar complementando atividades, projetos de conscientização, discussão e conteúdos disciplinares.

A realização da leitura literária é suficiente em si, basta-se. Entretanto, no ambiente escolar, no processo de formação inicial do leitor, o mediador é fundamental; pois oportuniza a compreensão da obra, o acesso a leituras e discussões, o encontro entre obra e leitor. Para Cosson:

[...] Ler para o outro nunca é apenas oralizar um texto. Leitor e ouvinte dividem mais que a reprodução sonora do escrito, eles compartilham um interesse pelo mesmo texto, uma interpretação construída e conduzida pela voz, além de outras influências recíprocas que, mesmo não percorrendo os caminhos sugeridos pela ficção, são relações importantes de interação social (COSSON, 2019, p. 104).

E quando pensamos nos alunos das escolas de rede pública, selecionar livros ganha um peso ainda maior, uma vez que muitos deles terão o primeiro contato com livros no âmbito escolar, e dependem única e exclusivamente da escola para se tornar um leitor competente e autônomo (COLOMER, 2007), um desbravador de boas histórias literárias. Diante disso, é crucial que todos os envolvidos nesse processo assumam seus postos e responsabilidades.

\section{REFERÊNCIAS}

ASEVÊDO. F. Programa Educação pra Valer. 2019. Disponível em: $<$ https://www.bastidoresdapoliticapb.com.br/luciano-cartaxo-assina-termo-de-cooperacaocom-o-programa-educacao-pra-valer-para-ampliar-resultados-do-geracao-alfabetizada/> Acesso em: 27 abr. 2020.

BRASIL. Fundação Lemann. Educar pra Valer: apoio para mais municípios em 2019. 2019. Disponível em: <https://fundacaolemann.org.br/noticias/educar-pra-valer-apoiopara-mais-municipios-em-2019> Acesso em: 28 abr. 2020.

Edital PNLD Literário. Ministério da Educação. Fundo Nacional de Desenvolvimento da Educação. Programa Nacional do Livro e do Material Didático Literário. Disponível em: <https://www.fnde.gov.br/index.php/programas/programas-dolivro/consultas/editais-programas-livro/item/11568-edital-pnld-liter\%C3\%A1rio $>$. Acesso em: 20 abr. 2020. 
de Desenvolvimento da Educação. Ministério da Educação, 2018. Disponível em: $<$ https://pnld.nees.com.br/assets-pnld/guias/Guia_pnld_2018_literario_2018literario_ensino_fundamental.pdf $>$ Acesso em: 20 abr. 2020.

COELHO, N. N. A literatura infantil: abertura para a formação de uma nova mentalidade. In.: _ Literatura infantil: teoria, análise, didática. 1.ed. São Paulo: Editora Moderna, 2000.

COLOMER, T. Critérios de avaliação e seleção de livros infantis e juvenis. In.:

Introdução à literatura infantil e juvenil atual. Tradução: Laura Sandroni. 1.ed. São Paulo: Editora Global, 2017.

Andar entre livros: a leitura literária na escola. Tradução: Laura Sandroni. São Paulo: Editora Global, 2007.

COSSON, R. As práticas da leitura literária. In: Círculos de Leitura e Letramento Literário. São Paulo: Editora Contexto, 2019.

MOTA, R. J. C. Avaliação pedagógica de obras literárias. Educação, v. 35, n. 3, p.308318, set./dez., 2012.

Recebido em: 03 jul. 2020.

Aceito em: 24 ago. 2020. 